\title{
Por uma abordagem tensiva do fait divers
}

\section{Towards a tensive approach to fait divers}

Conrado Moreira Mendes

PUC Minas

conradomendes@yahoo.com.br

Resumo: Neste artigo, propõe-se uma abordagem baseada na Semiótica tensiva para ofait divers. A expressão, que advém da imprensa francesa do século XIX, reporta-se a acontecimentos inusitados, fortemente marcados por um caráter emocional. A primeira abordagem estrutural do fait divers se deve a Barthes. Diferentemente desse autor, no entanto, e com base nas ideias de Zilberberg sobre a noção de tensividade, apresenta-se um modelo que concebe as categorias duração e memória como constitutivas desse tipo de relato. Ademais, apresenta-se uma tipologia tensiva, a partir da qual pode-se classificar o fait divers quanto à intensidade e à extensidade.

Palavras-chave: Semiótica francesa; tensividade; fait divers.

Abstract: In this study, we propose an approach based on tensive semiotics to fait divers (feature story). The term, which comes from the French press of the nineteenth century, refers to unusual events, strongly marked by an emotional character. The first structural approach to fait divers relates to Barthes. In contrast to this author, however, and based on Zilberberg's ideas about the concept of tensivity, we present a model that conceives the categories duration and memory as constituting such 
kind of report. In addition, we present a tensive typology, from which one can classify fait divers regarding intensity and extent.

Keywords: French Semiotics; tensivity; fait divers.

Recebido em 05 de março de 2015. Aprovado em 25 de setembro de 2015.

\section{Introdução}

Neste artigo, com base em nossa pesquisa de doutorado (MENDES, 2013a), propomos uma abordagem fundamentada na gramática tensiva (FONTANILLE; ZILBERBERG, 2001; ZILBERBERG, 2007; 2011a; 2011b) para ofait divers. Esse termo, que remonta à imprensa francesa da segunda metade do século XIX, refere-se a notícias que não se enquadram nas editorias tradicionais do jornalismo, como política, economia, cultura, internacional etc. O Grand Dictionnaire Universel du XIXe siècle, de Pierre Larousse, apresenta o verbete fait divers da seguinte maneira:

Sob essa rubrica, os jornais agrupam com arte e publicam regularmente todo tipo de notícias que correm pelo mundo: pequenos escândalos, acidentes de carros, crimes hediondos, suicídios por amor, pedreiro caído do quinto andar, assaltos, chuvas de gafanhotos ou de sapos, naufrágios, incêndios, inundações, aventuras burlescas, sequestros misteriosos, execuções fatais, casos de hidrofobia, de antropofagia, de sonambulismo, de letargia $[. .$.$] fenômenos da natureza [\ldots]$ bezerros de duas cabeças, [...] gêmeos grudados pelo ventre, criança com três olhos, anões extraordinários etc. (LAROUSSE, [1866-75], p. 58).

O uso do termo verificou-se, pela primeira vez, no periódico parisiense Le Petit Journal, de Moïse Polydore Millaud, lançado em $1^{\circ}$ de fevereiro de 1863 (MEYER, 1996, p. 98). A expressão, desde então, é largamente utilizada. E, embora se reporte ao advento da imprensa de massa, segundo Dion (2007, p. 127), esse tipo de notícias havia muito antes de sua veiculação nos jornais. Suas narrativas estavam relacionadas 
a um tipo de espetáculo cultural, em que o público participava e cuja transmissão era eminentemente oral. Nesse sentido, Ramos (2008, p. 137) afirma que o fait divers "já existia em diferentes produções culturais, na Idade Média, habitando os cantos dos menestréis, em seus apelos e interpelações de entretenimento". Barthes (1964, p. 194), que define o termo como "uma informação monstruosa", foi o primeiro teórico a lançar luz sobre esse tipo de relato, e a especificidade de sua abordagem reside em conjecturar uma estrutura para ofait divers.

Também nos ocupamos da estruturação desse gênero. Fazemolo, conforme anunciamos, à luz da Semiótica tensiva. Chamada por Zilberberg (2011a, p. 12) de "gramática do afeto", tal teoria volta seu interesse ao aspecto sensível da significação, às gradações, ao acontecimento, concebidos na tensão entre intensidade e extensidade. A nosso ver, ao se estabelecer uma perspectiva tensiva para o fait divers, criam-se condições para se vislumbrar um modelo de maior poder heurístico para sua abordagem que, sendo mais abstrato, será, por conseguinte, mais econômico.

Este artigo divide-se da seguinte maneira: trazemos, num primeiro momento, a definição semiológica de Barthes (1964) para o fait divers, bem como suas características e o que nos parece constituir limitações do modelo. Em seguida, apresentamos um panorama da gramática tensiva e uma abordagem a partir dessa perspectiva teórica para a categoria noticiosa em questão e, finalmente, propomos uma tipologia do fait divers, com base nos termos da Semiótica tensiva.

\section{Modelo semiológico do fait divers}

Ao explicar o conceito de fait divers, Barthes (1964) o diferencia de outras editorias jornalísticas ao comparar dois tipos de assassinato: um, por razões políticas, e um segundo, como sendo um crime passional. Para o autor, o assassinato do primeiro tipo sempre remeterá a um conhecimento exterior ao fato propriamente dito, ou seja, à conjuntura política, às razões daí decorrentes que motivaram tal assassinato etc. "em suma, o assassinato escapa ao fait divers sempre que ele for exógeno, vindo de um mundo já conhecido [...]. O assassinato político é, portanto, sempre uma informação parcial" (BARTHES, 1964, p. 195). O fait divers, conforme o semiólogo francês, ao contrário, prescinde de dados pré-existentes, constitui-se como uma informação total, "[já que] contém 
em si todo o saber: não é necessário nada do mundo para consumir um fait divers; ele não remete formalmente a nada senão a si próprio" ( $\mathrm{p}$. 195). Seu conteúdo, entretanto, não é estranho à "realidade" que nos cerca: são geralmente desastres, mortes, acidentes e bizarrices em geral.

Pela concepção barthesiana, as relações imanentes ao fait divers podem ser de dois tipos. A primeira é a de causalidade, em geral, aberrante. Por isso, ele traz consigo "um germe de degradação" (BARTHES, 1964, p. 197). Esse tipo de estrutura subdivide-se em duas formas de causalidade: a causa perturbada e a causa esperada. $\mathrm{Na}$ do primeiro tipo, não se conhece a causa do evento, ou, ainda, uma pequena causa gera um grande efeito. No segundo tipo de causalidade, a importância da relação perde força - ainda que continue presente - e a ênfase é posta sobre o que autor chama de dramatis personae, como, por exemplo, uma criança, um idoso, uma madrasta - "tipos de essências emocionais, encarregadas de dar vida a um estereótipo" (p. 197).

O segundo tipo de relação imanente, segundo Barthes, é o de coincidência, o qual se subdivide, igualmente, em dois subtipos: repetição e antítese. Alguém que ganha na loteria mais de uma vez, ou, ainda, contrariando a expressão popular, um raio que cai duas vezes no mesmo lugar, constituem um fait divers pelo caráter inesperado da repetição. No caso da antítese, duas lógicas opostas constituem esse tipo de relação imanente.

Cabe dizer ainda que, por essa proposição, não há fait divers sem o susto, sem o espanto de quem vê, lê ou assiste. A temática pode ser ainda de dois tipos: crimes (crimes passionais, suicídios, chantagens, agressões sádicas) e fenômenos (prodige) da ordem do inesperado, tais como notícias sobre supostos discos voadores, acontecimentos paranormais, fenômenos religiosos etc. Dion (2007, p. 126), nesse sentido, destaca a pouca variabilidade temática do relato noticioso em questão: "de fato, parece que o fait divers é eminentemente repetitivo". Observa-se, entretanto, uma particularidade desse pequeno inventário temático: são sempre marcados por um forte caráter fortuito e emocional.

Barthes (1964), nesse ensaio pleno de ideias, lança luz para o estudo do fenômeno dos faits divers, e indica caminhos capazes de suscitar ainda outras questões. Propomos fazê-lo, conforme anunciamos, pelo viés da Semiótica tensiva. Antes, entretanto, é necessário sublinhar a diferença entre o que Barthes (1964) entende por estrutura/imanência e como o faz a Semiótica de bases greimasianas. 
Para a Semiótica, a definição de Barthes para tais notícias (a exemplo do crime político - que necessitaria de informações exógenas a ele mesmo - diferente de um crime passional), apesar de estrutural, não constituiria sua imanência. Aos olhos da disciplina de Greimas, são preliminarmente as relações intratextuais ali engendradas que criariam efeitos de sentido específicos desse tipo de relato. É por esse caminho, portanto, que conduzimos nossa abordagem do fait divers.

Pela exemplificação de Barthes, a não necessidade de contexto especificaria o fait divers, enquanto sua imprescindibilidade definiria aquilo que não o é. Sem pretender fazer uma leitura estrita da máxima greimasiana, segundo a qual "fora do texto não há salvação" (GREIMAS, 1974, p. 25), admitimos que são suas próprias categorias em relação que definem tal imanência. Desse modo, o conceito de estrutura, segundo Hjelmslev (1991, p. 29), "entidade autônoma de dependências internas", ao qual subjaz o conceito de imanência, encontra-se, a nosso ver, atual para o estudo das relações intratextuais de quaisquer textos, entendidos em sentido lato.

Por isso, como se vê, o modelo semiológico de Barthes (1964), ainda que trate da "estrutura do fait divers", como indica o próprio nome do texto, apresenta limitações no que tange à questão da imanência e, portanto, à própria noção de estrutura. Além disso, para tal abordagem, o fait divers não possui duração nem memória, definição que, a nosso ver, parece questionável.

Sobre a duração desse tipo de relato, assevera Barthes (p. 195; grifos nossos): "sem duração e sem contexto, ele constitui um ser imediato, total, que não remete a nada de implícito [...]. É sua imanência que define o fait divers". Assim, para o autor, a duração, quer entendida como temporalidade, quer entendida como serialidade, não se aplicaria ao fait divers, pelo fato de esse ter uma natureza imanente. Nesse sentido, declara Alencar (2005), na esteira de Barthes:

Este [o leitor] é seduzido pelo princípio de uma desorganização generalizada, como se algo viesse dizer que a vida é assim mesmo, irrisória, vertiginosa, confusa. Os outros tipos de notícia se aproximam do romance, expressão da totalidade e da longa duração, que supõe uma serialidade que ofait divers desconhece (ALENCAR, 2005, 118-119; grifos nossos). 
A respeito da memória, afirma o semiólogo: "certos faits divers se desenvolvem por vários dias ou até meses; isso não rompe sua imanência constitutiva, pois implicam sempre uma memória curta" (BARTHES, 1964, p. 95; grifos nossos). Assim, segundo o autor, o fait divers não possui nem temporalidade, nem memória, ou, ainda, uma memória curta, isto é, que tende necessariamente a desaparecer.

Ora, em termos semióticos, essa justificativa não seria logicamente possível, uma vez que tanto a duração (seja em termos de temporalidade ou serialidade) quanto a memória, que advém da temporalidade, constituem-se na imanência do discurso, não podendo, pois, ser exteriores a ele.

Assim, tendo apresentado as características do modelo barthesiano do fait divers, acreditamos que, na atualidade, é relevante observar se a categoria jornalística em pauta é passível de acolher novas proposições. Desse modo, não obstante a estrutura que lhe propôs Barthes (1964), pelo que procuramos demonstrar neste artigo, duração e memória são categorias que subjazem ao fait divers a partir de um ponto de vista gradativo. Antes de proceder à abordagem tensiva, cumpre, contudo, apresentar alguns elementos basilares da teoria em questão.

\section{Algumas palavras sobre Semiótica tensiva}

Em linhas gerais, a Semiótica tensiva concede espaço privilegiado ao contínuo e à afetividade no discurso. Quanto à continuidade, cabe dizer, de início, que se a significação se constitui a partir de unidades discretas, a essa discretização subjaz um continuum, que já é uma potencialidade de sentido (GREIMAS; FONTANILLE, 1993, p. 10, 15). Desse modo, o ponto de vista tensivo estabelece-se em complemento à Semiótica greimasiana. Não se trata, assim, de trocar o discreto pelo não discreto, pois, como afirma Zilberberg (2011a, p. 16): “a 'casa do sentido' é vasta o bastante para acolher tanto o contínuo, quanto o descontínuo, mesmo porque nem este nem aquele fazem sentido por si mesmos, mas apenas por sua colaboração". Assim, a Semiótica tensiva oferece à teoria greimasiana a noção de gradação, sem a qual não seria possível analisar determinados fenômenos cuja característica principal não é a oposição, mas a diferença em algum grau, ou, nas palavras de Zilberberg (2011a, p. 14), o "intervalo". No que se refere à afetividade, para Fontanille (2007, p. 75), o modelo teórico em questão contempla as conexões entre o sensível 
e o inteligível, respeitando a complexidade dos fenômenos tal como se apresentam no discurso. Também, para Zilberberg (2011a, p. 45), "a particularidade do ponto de vista tensivo [consiste em] discernir as condições de uma reciprocidade ininterrupta do afeto e da forma". Dessa maneira, a teoria tem como um dos pressupostos fundamentais a gramaticalização do afeto.

Para tanto, por tal perspectiva, um fato semiótico é condicionado, ou, ainda, só tem existência Semiótica no e pelo espaço tensivo. Este é formado pela projeção do eixo da intensidade (relativa aos estados de alma) sobre o eixo da extensidade (relativa aos estados de coisas), o qual recebe e qualifica as grandezas que têm acesso ao campo de presença. Tal espaço é fundamentalmente complexo, pois é produto da relação necessária entre sensível e inteligível. Assim, qualquer ponto dentro do espaço tensivo corresponderá a um fato semiótico que, obrigatoriamente, terá uma valência em termos de intensidade e outra valência em termos de extensidade. Veja-se o seguinte diagrama:

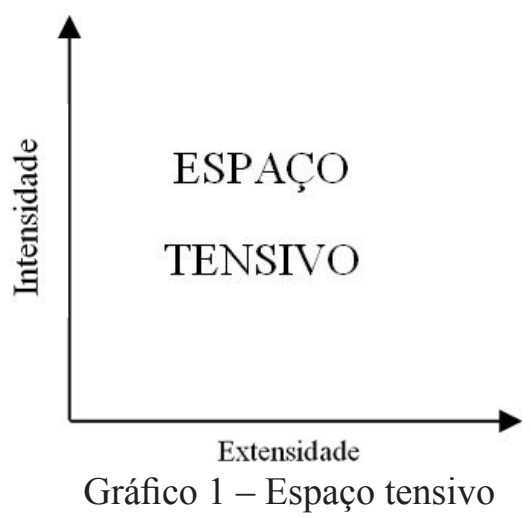

Fonte: elaborado pelo autor, baseado em Zilberberg (2011a)

O eixo da intensidade opera por meio dos pares [impactante vs. tênue]; o eixo da extensidade, por sua vez, pelos pares [concentrado vs. difuso]. São esses pares que controlam o acesso ao campo de presença. Assim, no que tange à intensidade, uma grandeza acessa o campo de presença de forma proporcional à quantidade de impacto que carrega consigo e, em termos de extensidade, ela será mais ou menos difusa, a partir das operações de mistura e triagem, conforme pode ser visto no Gráfico 2. 


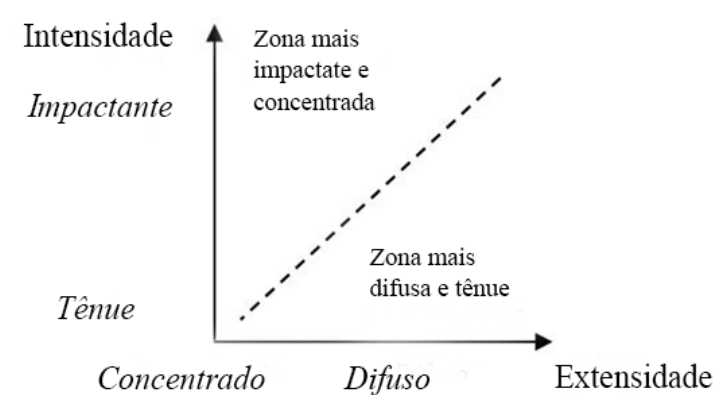

Gráfico 2 - Regiões do espaço tensivo

Fonte: elaborado pelo autor, baseado em Zilberberg (2011a)

Assim, quanto mais um fato semiótico tender à concentração, mais ele será guiado pelos valores de absoluto. Por outro lado, quanto mais esse fato se inclinar à difusão, mais ele será governado pelos valores de universo. No caso dos valores de absoluto, entram em jogo as operações de triagem; no caso dos valores de universo, opera-se por mistura.

Zilberberg (2011a, p. 93), além disso, prevê dois tipos de correlação entre intensidade e extensidade. Na correlação inversa, quanto maior a intensidade, menor a extensidade; na conversa, quanto maior a intensidade, maior será a extensidade, e vice-versa para ambos os casos. Nos gráficos a seguir, tais relações estão representadas:

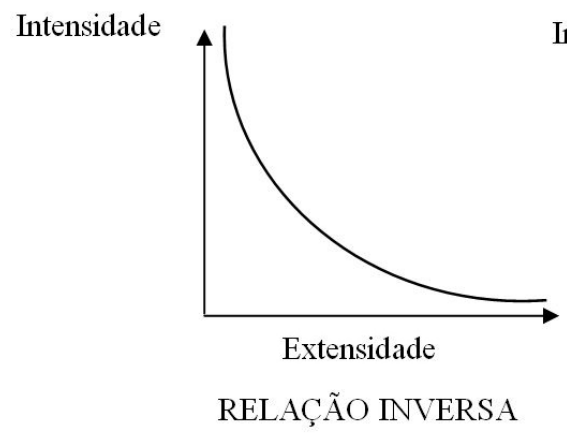

Intensidade

Gráfico 3 - Tipos de relações no espaço tensivo

Fonte: elaborado pelo autor, baseado em Zilberberg (2011a) 
Tendo sido considerados alguns conceitos fundamentais em Semiótica tensiva, passemos à definição de acontecimento, fundamental à abordagem tensiva do fait divers. Em termos semióticos, este é produto das subdimensões paroxísticas "andamento" e "tonicidade", as quais compõem a dimensão da intensidade. Dito de outro modo, é o fruto da velocidade aguda de um evento com sua energia e força de impacto no sujeito. Andamento e tonicidade agem juntos perturbando o sujeito por meio de uma "tempestade modal" (ZILBERBERG, 2011a, p. 236) instantânea, deixando-lhe apenas um sofrer que se sobrepõe ao agir. Diz Zilberberg (2011a, p. 163): "o acontecimento, por ser portador do impacto, manifesta enquanto tal que o sujeito trocou 'a contragosto' o universo da medida pelo da desmedida" (grifos do autor). Noutros termos, o acontecimento significa levar a afetividade ao auge, e tornar temporariamente a intelecção nula. No que se refere às subdimensões da extensidade, a temporalidade é extinta - o tempo fica "fora dos eixos". O mesmo se pode dizer da espacialidade, pois o sujeito, estupefato, vêse "fincado" no chão, ou, num lapso de tempo, engolido por um buraco negro, retirado de sua própria ambiência.

No diagrama a seguir, representa-se graficamente o acontecimento, na parte superior esquerda do espaço tensivo, e o exercício, na porção inferior direita:

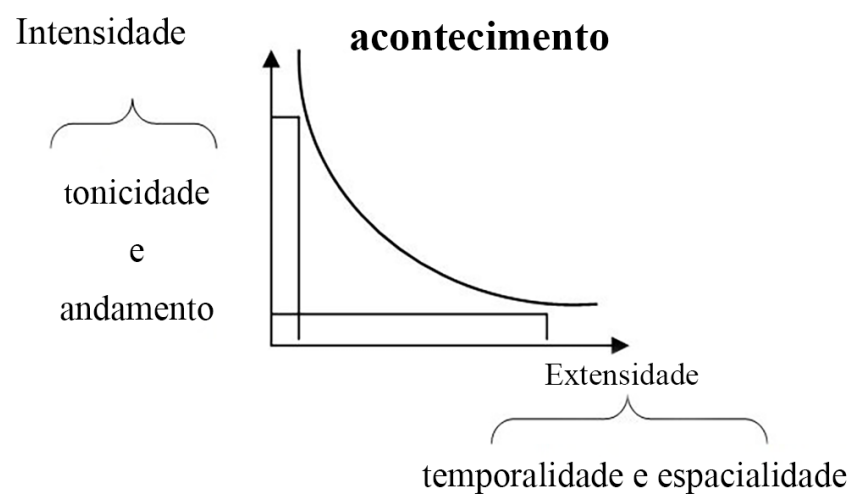

Gráfico 4 - Acontecimento e exercício

Fonte: elaborado pelo autor, baseado em Zilberberg (2011a) 
Cabe dizer que acontecimento e exercício são, pois, duas grandes orientações discursivas. A primeira corresponderia à problemática do surpreendente, do inesperado, regido por uma lógica concessiva. A segunda, à questão da narratividade que, por anos, foi o principal foco de interesse da Semiótica, a qual, por sua vez, é governada pela lógica implicativa (se... então) e, que, serve de base a toda a Semiótica clássica (ZILBERBERG, 2011b).

Zilberberg (2007, p. 25) estabelece três modos - eficiência, existência e junção - cujos respectivos termos configuram os estilos discursivos do acontecimento e do exercício. O modo de eficiência designa "a maneira pela qual uma grandeza se instala num campo de presença" (Id., 2007, p. 18). Se a grandeza se instala lentamente, configura-se a modalidade do pervir. Se, ao contrário, penetra abruptamente, há a modalidade do sobrevir. O modo de existência, por sua vez, refere-se à alternância entre os pares foco e apreensão. Tais termos se referem ao correlato subjetal dos termos pervir e sobrevir. No caso do foco, há um sujeito operador que age muito próximo ao sujeito do fazer; não há surpresas, mas relações pressupostas, tais como no esquema narrativo. $\mathrm{Na}$ apreensão, ocorre o contrário; não se trata mais de um sujeito do fazer, mas um sujeito de estado que sofre, que suporta, que, enfim, é invadido pelo objeto que surge ex abrupto. O modo juntivo relaciona, por sua vez, a concessão e a implicação:

No caso da implicação, o direito e o fato se respaldam mutuamente. Sua esfera é a da implicação: "se a, então b" e geralmente da causalidade legal. [...] No caso da concessão, o direito e o fato estão em discordância um do outro. Ela tem como emblema a dupla formada pelo embora e pelo entretanto: "embora a, entretanto não b" (ZILBERBERG, 2007, p. 23).

Para o autor (2007, p. 25), o estilo discursivo do acontecimento se define estruturalmente a partir de cada um dos pares dos modos de eficiência, de existência e de junção, a saber: o sobrevir, a apreensão e a concessão. O estilo discursivo do exercício, por sua vez, tem sua estrutura composta dos termos pervir, foco e implicação, a partir dos modos já mencionados. A seguir, apresentamos de forma esquemática a estrutura do acontecimento e do exercício: 
Tabela 1 - regimes do acontecimento e do exercício

\begin{tabular}{l|l|l}
\hline $\begin{array}{c}\text { determinados } \\
\text { determinantes }\end{array}$ & ACONTECIMENTO & \multicolumn{1}{|c}{ EXERCÍCIO } \\
\hline modo de eficiência & sobrevir & pervir \\
\hline modo de existência & apreensão & foco \\
\hline modo de junção & concessão & implicação \\
\hline
\end{tabular}

Fonte: elaborada pelo autor, baseada em Zilberberg (2007)

\section{Abordagem tensiva do fait divers}

Em nossa pesquisa de doutorado (MENDES, 2013a), consideramos um corpus composto por: 60 reportagens, exibidas entre 31 de março de 2008 a 12 de maio de 2008 pelo Jornal Nacional, sobre o caso Isabella Nardoni; uma reportagem do jornal $O$ Globo ("Bebê é espancado até a morte, e casal é preso") publicada em 19 de julho de 2012; outra do Jornal Nacional ("Motorista de ônibus salva menina que caiu de janela em Nova York"), exibida em 17 de julho de 2012, além de reportagens sobre outros dois faits divers: os casos von Richthofen e Eloá Pimentel.

Tomando o referido corpus à luz da Semiótica tensiva, pudemos concluir que o fait divers, enquanto fato jornalístico em si, possui uma estrutura acontecimental, tal como também demonstramos em Mendes (2013b). Noutros termos, trata-se de um fato semiótico que adentra o campo de presença do sujeito com grau paroxístico de intensidade e grau mínimo de extensidade. Tal fato semiótico, para que possa ser assimilado em termos de inteligibilidade, deve perder paulatinamente em intensidade e ganhar em extensidade, de modo a formar uma relação inversa, isto é, quanto maior a extensidade, ou seja, o desdobramento temporal, menor a intensidade. Desse modo, considerar o fait divers como um fato semiótico de bases concessivas, isto é, um acontecimento, permite que, com base na gramática tensiva, proponhamos um modelo de maior poder heurístico para a abordagem dessa categoria noticiosa, pois, sendo mais abstrato, será, por conseguinte, mais econômico.

Entretanto, para além de considerar of fait divers um acontecimento enquanto fato jornalístico em si, em nossa referida investigação de doutorado, procuramos analisar as diversas estratégias de discursivização 
desse relato noticioso. É, portanto, a partir da discursivização dos faits divers que compuseram o corpus da pesquisa, que procuramos depreender as categorias subjacentes, a partir da vertente tensiva da Semiótica.

Por isso, a nosso ver, ao contrário do que propõe Barthes (1964), duração e memória são categorias que subsumem a discursivização do fait divers. Desse modo, consideramos inicialmente a categoria duração, para, em seguida, discorrer sobre a categoria memória. Além dessas, apontamos para o elemento constitutivo paixões que, invariavelmente, compõe esse tipo de relato jornalístico. Cabe complementar que tais (in) variantes depreendidas pelo corpus são balizadas pelas esquizias tensivas primordiais intensidade e extensidade. A partir delas, pode-se estabelecer o que chamamos de abordagem tensiva do fait divers.

\section{Duração}

Conforme pôde-se apresentar em Mendes (2013a), acerca da análise do caso Isabella Nardoni, a tonicidade aplicada sobre a temporalidade aumenta a duração, criando um efeito de persistência (ZILBERBERG, 2011a). Assim, como também se demonstrou em Mendes (2014a), tal fait divers caracteriza-se pela longa duração, não obstante a manutenção da intensidade. Tal persistência remete, no nível do discurso, ao encadeamento, à sequencialidade de reportagens sobre um mesmo tema. A manutenção de um mesmo fato sob os holofotes da mídia, no nível figural, por sua vez, refere-se à "extensivização" do intenso, e não à continuidade, uma vez que essa remeteria, no nível da narrativa, à conjunção. $\mathrm{O}$ acontecimento, cuja estrutura subsume o fait divers, por seu turno, define-se por ser essencialmente uma ruptura, uma quebra, em suma, uma disjunção no nível da narrativa.

Um fait divers, aqui tomado como um fato semiótico de bases concessivas, pode ter uma cobertura midiática de duração que pode variar de curta (pontual) a longa, entendendo tais termos como polos opostos de um continuum. Uma invariante, no entanto, é que todo fait divers é portador de uma elevada carga tímica, conforme já afirmamos. Essa intensidade tende a decrescer em algum momento no transcurso da temporalidade. Desse modo, estão em jogo algumas situações observadas no corpus:

(i) Uma intensidade que, se de início já é alta, amplia-se, chegando à saturação; 
(ii) A manutenção temporária da intensidade num nível elevado, estável, apesar da temporalidade, que, em algum momento vai perder força, mas não necessariamente extenuar-se;

(iii) O decréscimo lento da intensidade pela temporalidade;

(iv) $\mathrm{O}$ decréscimo rápido da intensidade pela temporalidade.

Os três primeiros casos são portadores de longa duração, com maior extensidade, portanto; o último, por sua vez, mais comum, tem duração curta. Cabe precisar que, tanto na situação (i) quanto na (ii), observamos, inicialmente, uma relação conversa, isto é, quanto maior a extensidade, maior a intensidade.

Cumpre salientar, entretanto, que o discurso dirige-se rumo à plenitude ou à nulidade (ZILBERBERG, 2011a, p. 49-60). Assim, do menos para o mais, temos a ascendência, e do mais para o menos, a descendência. É digno de nota ainda que ascendência e descendência são tanto oponíveis, quanto componíveis. Portanto, de forma correlata ao plano de expressão da fala, a exemplo dos prosodemas, no plano do conteúdo, por meio do par mais e menos, o discurso se constitui de "picos" e "vales" - ou seja, de momentos mais ou menos intensos. Dessa maneira, é possível unir uma relação conversa a uma inversa, de modo a obter-se uma parábola, na qual estão contemplados os movimentos de ascendência e descendência nessas situações, conforme vemos a seguir:

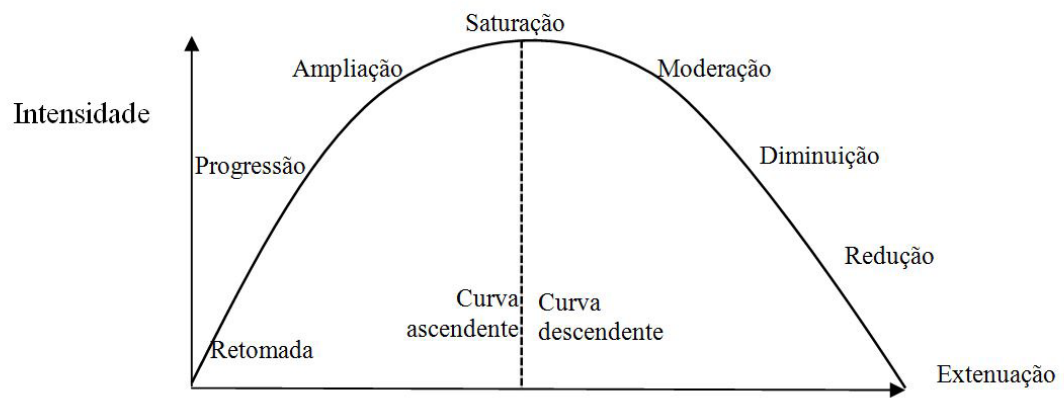

Extensidade

Gráfico 5 - Movimentos de ascendência e descendência no espaço tensivo Fonte: elaborado pelo autor 
O caso Isabella Nardoni, por exemplo, enquadra-se na situação (i), pois esse fato semiótico penetra no campo de presença do sujeito com uma intensidade elevada e que, por meio da categoria do recrudescimento, vai-se da unidade da ampliação rumo à saturação. A partir desse ponto, passa-se à moderação e, posteriormente, à diminuição. Não se pode dizer, entretanto, que tal fato semiótico chega a extenuar-se, o que significaria perder toda a sua carga tímica - o que nos remete à categoria memória (tratada na próxima seção).

As situações (iii) e (iv), por seu turno, são caracterizadas pela relação inversa, isto é, partem de uma intensidade elevada que, no transcurso da temporalidade, ganham em extensidade e perdem em intensidade. $\mathrm{O}$ que as diferencia, porém, é a celeridade da perda da intensidade, pois, no caso (iii), essa perda é lenta; e no (iv), rápida. A maioria das coberturas jornalísticas de faits divers - tal como a notícia veiculada pelo jornal $O$ Globo, sobre um bebê espancado, que não teve repercussão nos dias seguintes -, tem uma curva nitidamente descendente, perdendo a intensidade, extenuando-se num curto espaço de tempo.

Assim, nas situações (iii) e (iv), a saturação é o ponto máximo da intensidade. Um fait divers correlato ao acontecimento zilberberguiano parte dessa unidade e visa à moderação, em seguida, à diminuição que, por sua vez, tem como destino a redução, podendo chegar, por fim, à extenuação, tal como se vê no Gráfico 6.

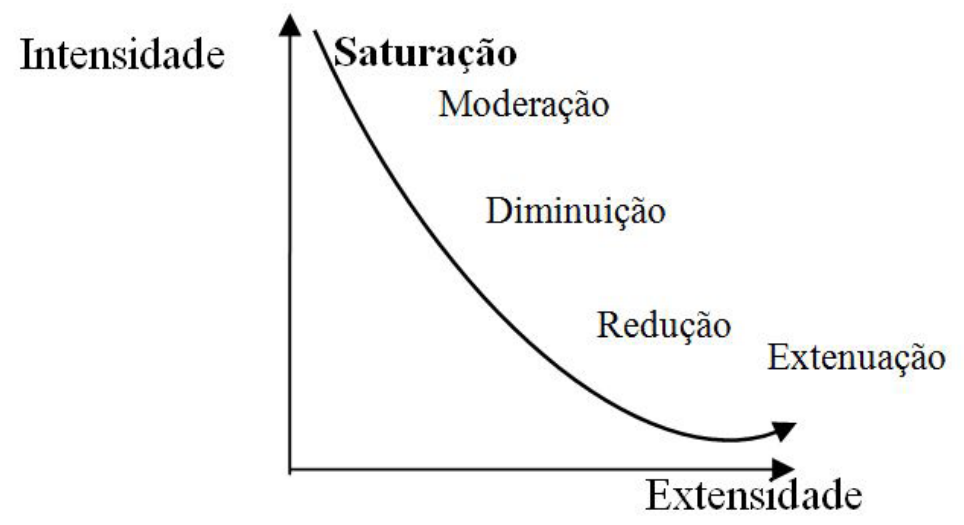

Gráfico 6 - Movimento de descendência

Fonte: elaborado pelo autor 
Levando-se em conta as situações acima descritas, invariavelmente, a partir da unidade da saturação, todas as discursivizações do fait divers são marcadas por uma curva descendente. O que vai diferir, nesse caso, é a velocidade do decréscimo de carga tímica em função do aumento da temporalidade.

Assim, em geral, o fait divers é portador de uma curta duração. No entanto, faits divers que, pela semântica extensiva, poderíamos denominar "raros" (por serem extensos e tônicos), possuem uma duração que extrapola uma ou duas edições de um programa jornalístico, estendendo-se - com considerável carga tímica - por um longo período. Tal "extensivização" do intenso é, portanto, o que caracteriza um fait divers dessa natureza.

\section{Memória}

Considerar a existência de uma duração variável do fait divers conduz a uma segunda categoria que, para nós, também abrange esse tipo de notícia: a memória. Assim, se um fato semiótico de carga tímica elevada permanece no campo de presença do sujeito (enunciatário) por um longo período, a memória em torno desse fait divers tende a permanecer, em função do longo período em que o sujeito semiótico foi afetado por aquele objeto.

Noutros termos, um fait divers que se realizou e cuja carga tímica, ainda, de alguma forma, subsiste entrará nas vias da potencialização. Com efeito, afirma Zilberberg (2007, p. 23) que "a potencialização está relacionada à memorização". Assim, aqueles faits divers que se mantêm potencializados de forma tônica estão diretamente ligados à memória, ao passo que aqueles que se potencializam de forma átona são esquecidos parcial ou totalmente.

Para Babo-Lança (2012, p. 55), "as mídias assumem um papel na construção da memória coletiva e uma vocação de cariz historiográfico, no sentido que elegem os acontecimentos dignos de memória". De forma correlata, Zilberberg (2011a, p. 193) declara que:

Atendo-se ao que se costuma chamar de "historietas", o jornal registra dia a dia os fatos menores que a pequenez do intervalo adotado lhe proporciona, enquanto a cronografia, ao se valer de um intervalo por vezes considerável, 
desacelera a passagem do tempo, quando não a suspende, e só seleciona os momentos considerados por uma ou outra razão "fortes", os "acentos de sentido", os quais encadeados uns aos outros, vão constituir ou parecer constituir a "grande história".

A asserção do semioticista se refere à diferença entre o banal do jornalismo diário e de fatos que, por algumas razões, entram para o rol da História, ou seja, os grandes acontecimentos que marcaram época. É possível, entretanto, valermo-nos da citação acima no sentido de elucubrarmos uma espécie de hipotética enciclopédia do fait divers. Nela, evidentemente, figurariam aqueles com alto grau de intensidade. Entretanto, estariam presentes, sobretudo, os que, além de um alto grau de intensidade, fossem marcados por uma grande duração, a qual, por sua vez, remete à memória.

Assim, como foi dito, a grande extensidade temporal em que se desenvolveu o caso Isabella Nardoni, aliada a sua alta carga tímica, caracteriza esse fait divers como do tipo "raro", segundo os termos da semântica extensiva, uma vez que é tônico e extenso. Desse modo, poderíamos considerar faits divers dos quais se esquecem facilmente, mas também aqueles em torno dos quais a memória permanece viva. Os primeiros se obliteram sob a sombra dos faits divers do dia seguinte. Entretanto, no outro polo desse continuum, estão aqueles faits divers cuja chama não se apaga por completo; reminiscentes, permanecem tônicos na memória coletiva.

Para nos mantermos no caso Isabella Nardoni, a notícia veiculada pelo jornal $O$ Globo em 19/07/2012 sobre o bebê espancado até a morte, que abriu uma nota dentro da reportagem principal para referir-se àquele fait divers, é, por exemplo, um indício inequívoco de que a memória em relação a ele subsiste nas vias da potencialização, como se lê a seguir:

O episódio que teve grande repercussão no país - e até no exterior - nos últimos tempos foi o assassinato de Isabella Nardoni, de 5 anos, em São Paulo. Ela foi jogada pela janela de seu apartamento, no sexto andar de um prédio na Zona Norte, em março de 2008, depois de ser asfixiada. Dois anos depois, o pai e a madrasta de Isabella, Alexandre Nardoni e Anna Carolina Jatobá, foram condenados 
por homicídio triplamente qualificado a 31 e a 26 anos, respectivamente (REBELLO, 2012, p. 14).

Podemos ainda comprová-lo com a seguinte notícia veiculada em 24/01/2013 pela Folha de S. Paulo, em cujo título se lê: "Peça de teatro sobre caso Isabella Nardoni estreia em SP em março". A notícia informa que:

Conhecido como "caso Isabella", o assassinato da menina Isabella Nardoni, aos cinco anos de idade, servirá de base a uma encenação teatral da companhia Os Satyros. Escrito por Lucas Arantes, o texto "Edifício London" será dirigido por Fabrício Castro com coordenação de Rodolfo García Vázquez. A estreia está prevista para março, em São Paulo. Isabella morreu no dia 29 de março de 2008 , ao ser jogada do sexto andar do prédio, edifício London, onde moravam o pai, Alexandre Alves Nardoni, e a madrasta da menina, Anna Carolina Trotta Jatobá. Eles foram condenados, em março de 2010, por homicídio triplamente qualificado e fraude processual (por ter alterado a cena do crime). A peça, no entanto, não faz uma reconstituição precisa do crime. (FIORATTI, 2013).

Cabe ainda citar uma reportagem publicada pelo portal de notícias G1 cujo título é "Condenação de Suzane Richthofen pela morte dos pais completa 4 anos". Assim, pode-se dizer que esse fait divers também permanece potencializado tonicamente.

Por conseguinte, se formos conceber um compêndio de faits divers brasileiros dos últimos 20 ou 30 anos, correlatos aos acontecimentos que compõem a História, segundo Zilberberg (2011a), e, naturalmente, deixando de lado os triviais, tal obra seria composta de poucas páginas. E por que razão? Da mesma forma que a História age pelo princípio da triagem, também é assim que operaria a sintaxe extensiva de uma possível enciclopédia de faits divers brasileiros das últimas duas ou três décadas.

\section{Paixões}

Faits divers com longa duração, persistentes, devido à projeção da tonicidade na temporalidade, são marcados, de maneira geral, 
pela paixão da comoção pública. Esse "sentir/sofrer-comum", como mostra Landowski (2004), conforma o social, um actante coletivo, cuja amálgama é a pura estesia. Assim, a comoção social em torno de faits divers é outra invariante que pudemos verificar no/pelo corpus.

Não apenas de comoção, entretanto, é feito um relato jornalístico dessa natureza. A partir do corpus referido, pudemos ratificar seu forte caráter ligado a outras paixões. Assim, são temas recorrentes desse tipo de relato crimes passionais, chantagens, agressões; em suma, fatos caracterizados por um forte quantum emocional. Pela sintaxe juntiva, o fait divers é marcado pela concessão, uma vez que remete a eventos da ordem do inesperado, do fortuito.

Cumpre dizer, ademais, que paixões relativas ao fait divers não se referem apenas ao intradiscurso. Assim, o fait divers se relaciona a outras narrativas estocadas em outros textos do imaginário humano, em que actantes sofrem ou fazem sofrer, movidos, em geral, por paixões malevolentes. No nível discursivo, tais actantes se actorializam sob a forma de uma "madrasta" ou uma "criança indefesa", resgatáveis facilmente por interdiscursividade ou intertextualidade.

Dessa forma, pode-se perceber que as paixões que marcam o fait divers o constituem tanto no que se refere aos atores do enunciado (em que se destacam as paixões de malquerença) quanto nas relações que se estabelecem entre atores da enunciação (principalmente a paixão da comoção), mas também nas relações intertextuais e interdiscursivas que se podem estabelecer entre um dado fait divers e outros textos/discursos.

\section{Tipologia tensiva do fait divers}

Sobre a diferença entre faits divers "raros" e "comuns", a partir da semântica extensiva, cabe dizer ainda que um fait divers pode ter uma intensidade variável sendo, por isso, mais átono ou mais tônico. Desse modo, relatos trágicos, mortes em geral, têm maior tonicidade que notícias relacionadas a eventos da ordem do inesperado, mas não necessariamente tônicas. Assim, para fazer uso do mesmo exemplo aqui já utilizado, a informação sobre alguém que ganha na loteria por mais de uma vez configura um fait divers átono. Logo, podemos postular a existência de faits divers tônicos e faits divers átonos (ou mais tônicos ou mais átonos, a partir de uma perspectiva gradual). Os primeiros se dividem em tônicos e concentrados, tal como a notícia do bebê espancado 
até a morte, e em tônicos e extensos, tal como o caso Isabella Nardoni. A seguir, podemos representar graficamente essa classificação:

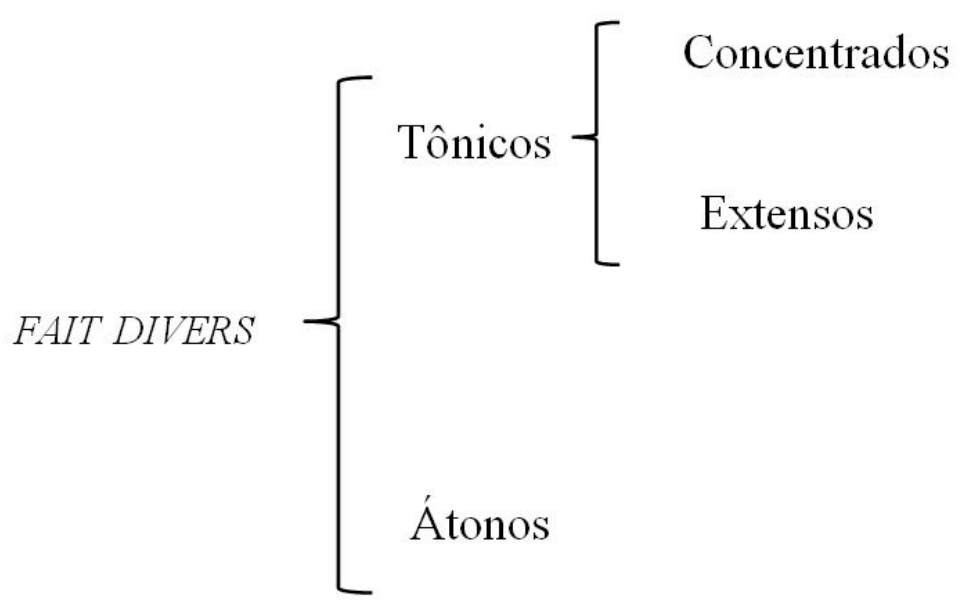

Figura 1 - Tipologia tensiva do fait divers Fonte: elaborada pelo autor

A partir dessa esquematização, torna-se possível uma classificação a partir do par "raro/comum", da semântica extensiva:

Tabela 2 - Tipologia tensiva do fait divers

\begin{tabular}{l|l}
\hline FAITS DIVERS COMUNS & FAITS DIVERS RAROS \\
\hline Átonos & Tônicos e extensos \\
\cline { 1 - 1 } Tônicos e concentrados & \\
\hline
\end{tabular}

Fonte: elaborada pelo autor

Assim, se a maioria dos faits divers se enquadra na primeira coluna, dos comuns, seja por possuírem menor tonicidade ou por serem tônicos e concentrados, os raros, por sua vez, diferenciam-se pela maior tonicidade e extensão temporal por que são caracterizados.

Cabe dizer ainda que faits divers "comuns" (sejam estes átonos ou tônicos) e concentrados, são aqueles cuja discursivização jornalística se dá pela correlação inversa, com grande exploração do eixo da 
intensidade, principalmente no segundo caso. Já os faits divers "raros", isto é, tônicos e extensos, dizem respeito à discursivização jornalística segundo a correlação conversa, apresentando, do mesmo modo, grande exploração do eixo da intensidade.

\section{Fait divers, acontecimento e exercício}

A duração, como se viu, evidenciou-se uma categoria do fait divers, depreendida por meio da estratégia discursiva que denominamos "extensivização" do intenso. Essa estratégia caracteriza uma engrenagem que articula dois regimes discursivos de que fala Zilberberg (2007, p. 25), a saber: o acontecimento e o exercício. Retomemos a tabela "Regime do acontecimento e do exercício", em que o autor define tais regimes por meio de três termos, cada qual correspondente a um modo.

Tabela 3 - Regimes do acontecimento e do exercício

\begin{tabular}{c|c|c}
\hline $\begin{array}{c}\text { determinados è } \\
\text { determinantes ê }\end{array}$ & ACONTECIMENTO & EXERCíCIO \\
\hline modo de eficiência & sobrevir & pervir \\
\hline modo de existência & apreensão & foco \\
\hline modo de junção & concessão & implicação \\
\hline
\end{tabular}

Fonte: elaborada pelo autor, baseada em Zilberberg (2007)

Zilberberg (2011a,p. 271) ainda sobredetermina os termos "sobrevir" (relativo ao acontecimento) e "pervir" (referente ao exercício) pelos termos andamento, temporalidade e número, conforme se reproduz a seguir:

Tabela 4 - Correlação entre sobrevir e pervir com andamento, temporalidade e número

\begin{tabular}{l|l|l}
\hline $\begin{array}{l}\text { definidos } \rightarrow \\
\text { definidores ê }\end{array}$ & SOBREVIR & PERVIR \\
\hline andamento & celeridade & lentidão \\
\hline temporalidade & $\begin{array}{l}\text { instantaneidade e indivisi- } \\
\text { bilidade }\end{array}$ & $\begin{array}{l}\text { duratividade e progressi- } \\
\text { vidade }\end{array}$ \\
\hline número & em uma só vez & em tantas vezes \\
\hline
\end{tabular}

Fonte: elaborada pelo autor, baseada em Zilberberg (2011a) 
No caso do fait divers cuja discursivização se dá de forma tônica e extensa, o sobrevir e o pervir tendem a uma sobreposição de modo a se formar um termo complexo. Vejamos, pois, como isso é possível.

No que tange ao andamento, esse tipo de fait divers se instaura com celeridade, pois todo o fait divers, como fato jornalístico em si, constitui-se como um acontecimento zilberberguiano. No entanto, graças a uma cobertura jornalística extensa, de longa duração, tal andamento, antes acelerado, em algum momento, passa a tender à lentidão. Em relação à temporalidade, tal como o acontecimento zilberberguiano, ele é instantâneo; no entanto, a partir dessa instantaneidade, é marcado pela duratividade, que é exatamente o que marca um fait divers extenso. No que concerne ao número, ele adentra o campo de presença do sujeito de uma só vez. Como exemplo, podemos citar o fato motivador do crime do caso Isabella Nardoni: seu assassinato. Entretanto, por meio do que chamamos em (MENDES, 2013a, p. 154) de microacontecimentos, isto é, eventos secundários que se relacionam a um evento principal e motivador, e da reverberação do acontecimento inicial, o "em uma vez só" passa a se realizar "em tantas vezes".

A apreensão, característica do acontecimento, ou seja, aquilo que toma o sujeito, invade-o, deixa-o sem a sua voz (ZILBERBERG, 2011a, p. 189), aplica-se ao fait divers que podemos chamar, pela semântica extensiva, de "comum". O fait divers de longa duração, por sua vez, estabelece um elo com o foco, que é quando o sujeito consegue elaborar, por meio da temporalidade, o sensível paroxístico, convertendo-o, ao menos parcialmente, em inteligível. Assim, por meio da duração, o fait divers que se estende no eixo da temporalidade articula sensível e inteligível, de modo a também respaldar nossa tese de que esse tipo de relato noticioso estabelece uma ponte entre os estilos discursivos acontecimento e exercício.

Por fim, quanto ao modo de junção de cada um desses regimes discursivos, podemos afirmar que o fait divers "comum" tem bases concessivas, assim como também tem of fait divers "raro", considerandose o fato jornalístico em si. Entretanto, esse último, por meio de uma discursivização que o faz durar, uma vez que se constitui como uma presença constante de um mesmo fato semiótico no campo perceptivo do sujeito, seja por reverberação, seja por microacontecimentos, move o acontecimento em direção à rotina. Dito de outro modo, o acontecimento não chega a ser absorvido pela cotidianidade, pelo exercício, o que 
significaria trocar o modo concessivo pelo implicativo, mas cria-se uma tensão entre esses dois regimes a partir da atenuação do intenso paroxístico.

Assim, o fait divers durativo, "raro", por meio da estratégia discursiva que "extensiviza" o intenso, articula, coloca em relação os regimes discursivos do acontecimento e do exercício a partir de um ponto de vista tensivo e, portanto, complexo.

\section{Considerações finais}

Pelo que procuramos demonstrar, neste artigo, a abordagem tensiva do fait divers permite afirmar, diferentemente de Barthes (1964), que ao fait divers subjazem as categorias duração e memória, depreendidas pela análise do corpus de nossa pesquisa de doutorado (MENDES, 2013a). Assim, o fait divers pode ser portador de duração e ficar potencializado de forma tônica na memória coletiva, mas isso não significa que necessariamente sempre o será. Cabe acrescentar que entendemos as categorias duração e memória como polos de uma gradação, ou seja: do menos durativo ao mais durativo; do menos memorável ao mais memorável. Por conseguinte, pela ótica tensiva, podese aventar um modelo que não aprisiona o fait divers numa temporalidade obrigatoriamente curta e numa memória igualmente breve. Pensar o fait divers pela perspectiva da tensividade possibilita correlacionar sensível e inteligível, intensidade e extensidade, de forma "elástica", contínua, complexa - apanágio da teoria em que nos apoiamos. Assim, a abordagem tensiva que postulamos para essa categoria jornalística é apta tanto para abarcar faits divers do tipo "raro" quanto do tipo "comum".

\section{Referências}

ALENCAR, M. A de. O que é o fait divers: considerações a partir de Roland Barthes. In: CASANOVA, V.; GLENADEL, P. (Org.). Viver com Barthes. v. 1. Rio de janeiro: Sete Letras, 2005. p. 115-128.

BABO-LANÇA, I. Acontecimento e memória. In: FRANÇA, V. R. V.; OLIVEIRA, L. de. Acontecimento: reverberações. Belo Horizonte: Autêntica, 2012.

BARROS, D. L. P. de. Paixões e apaixonados: exame semiótico de alguns percursos. Cruzeiro Semiótico, 11/12, 1990. p. 60-73. 
. Uma reflexão semiótica sobre a "exterioridade" discursiva. Revista Alfa, v. 2, n. 53, p. 351-364, 2009.

BARTHES, R. Structure du fait divers. In: . Essais critiques. Paris: Seuil, 1964.

DION, S. O fait divers como gênero narrativo. Revista Letras (UFSM), v. 34, p. 123-131, 2007.

DOSSE, F. A história do estruturalismo: o campo do signo - 1945/1966. vol. 1. Tradução A. Cabral. Bauru: EDUSC, 2007.

FIORATTI, G. Peça de teatro sobre caso Isabella Nardoni estreia em SP. Folha de S. Paulo, 2013. Disponível em: <http://www1.folha.uol.com.br/ ilustrada/2013/01/1220042-peca-de-teatro-sobre-caso-isabella-nardoniestreia-em-sp-em-marco.shtml>. Acesso em: 9 mai. 2016.

FONTANILLE, J.;ZILBERBERG, C. Tensão e significação. Tradução Ivã Carlos Lopes, Luiz Tatit e Waldir Beividas. São Paulo: Humanitas, 2001.

. Semiótica do discurso. Tradução Jean Cristtus Portela. São Paulo: Contexto, 2007.

. Práticas semióticas: imanência e pertinência, eficiência e otimização. In: DINIZ, M. L. V. P.; PORTELA, J. C. (Org.). Semiótica e mídia: textos, práticas, estratégias. Bauru: UNESP/FAAC, 2008.

GREIMAS, A. J. L'Énonciation: une posture épistémologique. Significação - Revista Brasileira de Semiótica, Ribeirão Preto, n. 1, p. 9-25, 1974.

GREIMAS, A. J.; FONTANILLE, J. Semiótica das paixões: dos estados de coisas aos estados de alma. Tradução Maria José Rodrigues Faria Coracini. São Paulo: Ática, 1993.

HJELMSLEV, L. Ensaios linguísticos. Tradução Antônio de Pádua Danesi. São Paulo: Perspectiva, 1991.

JORNAL NACIONAL. Site. Disponível em: <http://jornalnacional. globo.com/>. Acesso em: 9 maio 2016.

LANDOWSKI, E. Passions sans nom: essais de socio-sémiotique III. Paris: Presses Universitaires de France, 2004.

LAROUSSE, P. Fait divers. In: Grand Dictionnaire universel du XIXe siècle. v. 8. Paris: Librairie Classique Larousse et Boyer, 1866-1875. p. 58. 
MENDES, C. M. Semiótica e mídia: uma abordagem tensiva do fait divers. 2013. 282 f. Tese (Doutorado em Semiótica e Linguística) Faculdade de Filosofia, Letras e Ciências Humanas, Universidade de São Paulo, São Paulo, 2013a.

. Um olhar tensivo sobre a estrutura barthesiana do fait divers. Estudos Semióticos, São Paulo, v. 9, n. 2, p. 22-27, 2013 b.

. A extensão do acontecimento midiático: uma leitura semiótica pelos conceitos de fidúcia e concessão. CASA: Cadernos de Semiótica Aplicada, v. 12, n. 1, p. 259-290, 2014a.

. Dialogismo e tensividade. Estudos Semióticos, São Paulo, v. 10, n. 2, p. 45-52, 2014b.

MEYER, M. Folhetim: uma história. 2. ed. São Paulo: Companhia das Letras, 1996.

RAMOS, R. Caso Isabella: uma leitura semiológica. Significação (USP), n. 30, p. 137-147, 2008.

REBELLO, P. A violência em família. O Globo, 19 jul. 2012.

TATIT, L. Musicando a semiótica: ensaios. São Paulo: Annablume, 1997. ZILBERBERG, C. Louvando o acontecimento. Tradução Maria Lúcia Vissotto Paiva Diniz. Revista Galáxia, São Paulo, n. 13, p. 13-28, jun. 2007.

. Elementos de semiótica tensiva. Tradução Ivã Carlos Lopes, Luiz Tatit e Waldir Beividas. São Paulo: Ateliê Editorial, 2011a.

. Des formes de vie aux valeurs. Paris: PUF, 2011b. 